\title{
A new Experimental Rig for Oil Burning on Water - Results for Crude and Pure Oils
}

\author{
NICHOLAS L. BROGAARD ${ }^{1}$, MARTIN X. SØRENSEN ${ }^{1}$, JANNE FRITT-RASMUSSEN $^{2}$, ALI S. $^{2}$ \\ RANGWALA $^{3}$, GRUNDE JOMAAS $^{1}$ \\ ${ }^{1}$ Technical University of Denmark (DTU), Department of Civil Engineering \\ Brovej, Building 118 \\ DK-2800 Kgs. Lyngby, Denmark
}

${ }^{2}$ Danish Centre for Environment and Energy, Department of Bioscience, Aarhus University

Frederiksborgvej 399

DK-4000 Roskilde, Denmark

${ }^{3}$ Worcester Polytechnic Institute, Department of Fire Protection Engineering

100 Institute Road

Worcester, MA 01609, USA

\begin{abstract}
A new experimental apparatus, the Crude Oil Flammability Apparatus (COFA), has been developed to study in-situ burning of crude and pure oils spilled on water in a controlled laboratory environment with large water-to-oil ratios. The parameters and phenomena studied for an asphaltic crude oil (Grane) and two pure oils (n-Octane and dodecane) with different initial oil layer thicknesses include burning efficiency, burning rate, regression rate, flame height and boilover. Pyrex glass cylinders (157 and $260 \mathrm{~mm}$ ID) placed on top of a steel foot in a water basin $(1 \mathrm{~m} \times 1 \mathrm{~m} \times 0.5 \mathrm{~m})$ enabled free circulation of the water, which, along with the large water-to-oil ratios (up to 10,000) ensured that the oil burning barely increased the temperature of the surrounding water environment, which created more realistic offshore conditions than seen in many other laboratory studies. The burning efficiency was found to be nearly $100 \%$ for n-Octane and of dodecane, whereas the crude oil burning efficiency ranged between $35 \%$ and $65 \%$. The main reason for this variation proved to be the onset of an extremely violent boilover, which occurs for oils with relatively high boiling temperatures when the water sub layer is superheated. When the initial crude oil layer thickness exceeded $20 \mathrm{~mm}$ the oil became solid and no boilover occurred. The heat-loss to the water sub-layer also had an effect on the burning efficiency and the regression rate was found to reach a constant value after increasing continuously as the oil was heated. Similar results were found regarding the flame height which reached a steady flame height. The pure fuels, n-Octane and dodecane, produced a much higher steady flame height than the crude oil, however they did not reach boilover, though dodecane showed boilover tendencies. Theoretical predictions with existing correlations and input data specific for the current oils generally compared well with the experimental data for both the time to boilover and the regression rates. As such, the COFA is envisioned to produce high-fidelity results in the future and thereby contribute to the further development of in-situ burning as an alternative response technique for oil spills on water.
\end{abstract}

KEYWORDS: In-Situ Burning, Burning efficiency, Burning rates, Boilover, Crude oil.

\section{INTRODUCTION}

Marine oil spills are of major concern, in particular due to the large environmental impacts that follow an oil spill. Oil is toxic to almost all organisms, and the toxic effects depend on the composition and concentration of the oil and the sensitivity of the species affected [1]. Thus, an efficient oil spill response is essential to reduce and minimize the impacts seen from an oil spill. The generally preferred oil spill response method is containment and recovery, as it is the only method that removes the contamination from 
the spill site. However, the Alternative Response Technologies (ART); in-situ burning and chemical dispersants are subject to increasing interest due to the methods' applicability and high efficiency in situations where containment and recovery could have limited use. Recently, both chemical dispersants and in-situ burning were used in the Macondo deep-water well incident (Deepwater Horizon explosion) in the Gulf of Mexico [2].

In-situ burning is a method where the accidentally spilled oil is ignited and burned at the spill site, and a large amount of the oil is thereby converted into $\mathrm{CO}_{2}$, water, soot and other combustion products. Burning effectiveness higher than $90 \%$ has been found under the right circumstances (fresh oil and thick oil slick) $[3,4]$, but weathered oils can also be ignited with high removal effectiveness [5]. At the end of the burning, a residue remains on the sea surface that must be handled. Several studies have been conducted over the last $30-40$ years related to investigating different controlling parameters that influence the ignitability, efficiency, and flame spread of the process [6-13]. Many of these studies (except those carried out on the large scale) depended on the experimental apparatus that was used to study the problem. This dependency was resolved in many studies with modeling and experimental analysis of the fuel-layer and water interface. This was necessary due to the disparity in some of the results of the large scale and bench scale testing. For example, Evans [14] reports that the enhancement of burning rate due to presence of water layer boilover below the oil can be more than a factor of two when comparing bench scale testing with large burns in open water $[15,16]$. One reason for this discrepancy may be the insufficient water layer surrounding the fuel. Unlike in the ocean, where the large scale burns reported by Evans [14] were performed, the bench scale testing may have significant heat transfer due to heating up of the container holding the fuel as well as heat transfer due to recirculation of water in the set-up. For example, many fuel containers had diameters in the range of $15-50 \mathrm{~cm}$, heights of only $6 \mathrm{~cm}$, and were conducted in stainless steel pans with no surrounding water, and with oil layers ranging from 2 to $20 \mathrm{~mm}$. Some pans were even larger (Koseki et al. [16] used $1 \mathrm{~m}$ diameter). It can be argued that this condition is not comparable to an actual burn in open sea, mainly because the surrounding water is (a.) not sufficient in quantity or (b.) not surrounding the pan. This experimental difficulty was to some extent overcome by the development of models to represent the heat transfer mechanisms between the oil-water interface [12, 13, 17-19]. However, there are still significant uncertainties associated with the value of parameters obtained using bench scale tests and their interpretation/extrapolation to application of in-situ burning in the open seas.

With the above considerations in mind, the objective of the current study was to develop an experimental laboratory apparatus, which could represent realistic full scale conditions such that extracted flammability parameters can be transferred directly to the field. To achieve this, the Crude Oil Flammability Apparatus (COFA), was designed amongst others to have a larger body of water, to create an oil/water interface comparable to large scale. The COFA has been verified against experimental data from large scale field experiments [10]. The objective of this paper is to provide a description of the development of the COFA, and present preliminary results and their application.

\section{EXPERIMENTAL DESIGN AND PROCEDURE}

A conceptual drawing of the newly developed experimental apparatus, the Crude Oil Flammability Apparatus (COFA), is shown in Fig. 1. The oil-on-water burning experiments were conducted with the oil contained by two different Pyrex Glass Cylinders (PGC) with a height of $340 \mathrm{~mm}$ and diameters of 157 $\mathrm{mm}$ and $260 \mathrm{~mm}$, respectively. The PGC was placed in the middle of a stainless steel water bath of $1.0 \mathrm{x}$ $1.0 \times 0.50 \mathrm{~m}(\mathrm{~L} \mathrm{x} \mathrm{W} \mathrm{x} \mathrm{H)} \mathrm{that} \mathrm{was} \mathrm{placed} \mathrm{under} \mathrm{an} \mathrm{exhaust} \mathrm{system} \mathrm{(see} \mathrm{Fig.2).} \mathrm{Two} \mathrm{of} \mathrm{the} \mathrm{sides} \mathrm{in} \mathrm{the}$ water bath were made of Plexiglas to allow for visual inspection of the oil layer regression rate and potential heavy residue formation and sinking. A stainless steel foot for the PGC was used to ensure free water flow underneath, which is important for minimizing the difference in the ullage height throughout the experiment. The bath was filled with water (390 liters of fresh water, $5-20^{\circ} \mathrm{C}$ ) until it nearly reached the top of the PGC. A known amount of oil was carefully placed inside the PGC on the water surface. Three types of oil were investigated; Grane (crude oil), n-Octane and dodecane. The initial oil layer thicknesses were 2$80 \mathrm{~mm}$, which resulted in water/oil ratios in the range of 500-10,000. Generally, the reproducibility of the 
experimental results was very good for the 2-3 experiments that were conducted for each data point, and the errors stayed within $\pm 10 \%$ variation of the reported data.

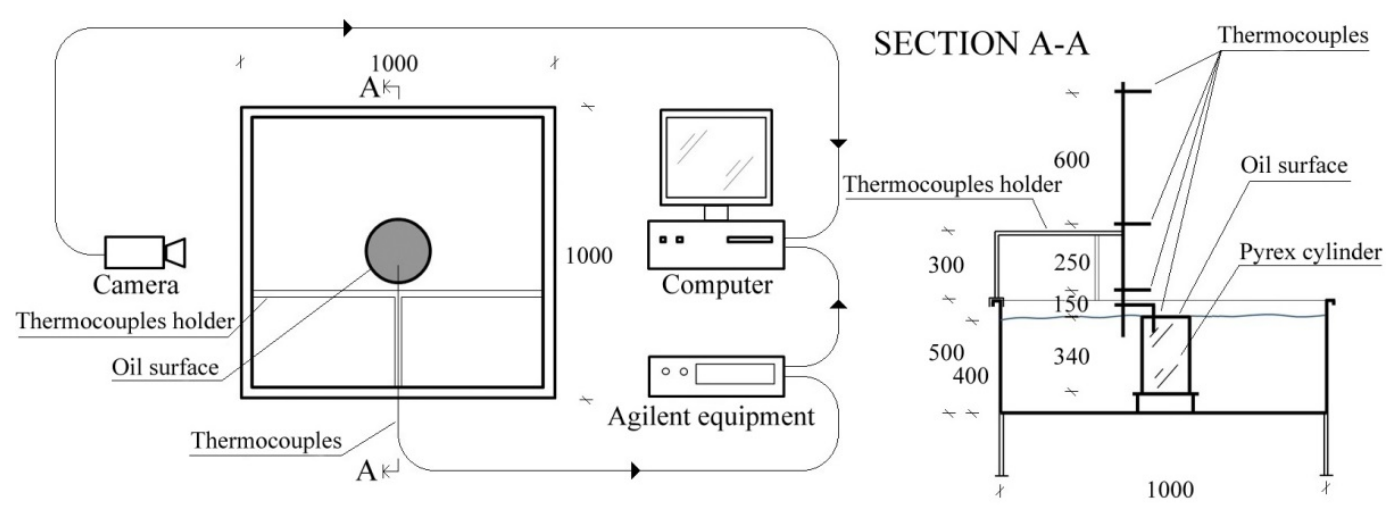

Fig. 1. Conceptual outline of the experimental setup. The COFA seen from above (left) and the experimental rig seen from the side, section A-A (right). All numbers are in mm.

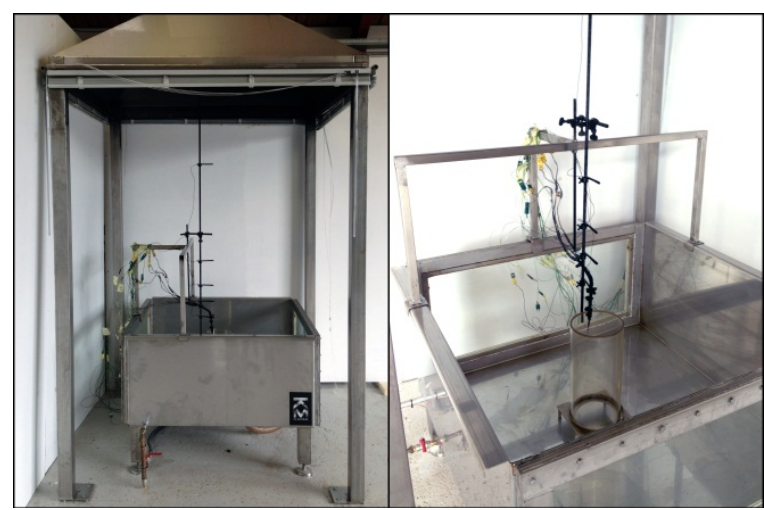

Fig. 2. Photographs of the COFA. The entire assembly under the exhaust hood (left) and the smaller PGC on top of the steel foot and the thermocouple array (right).

The exact oil slick thickness was calculated based on known values of the oils densities and the weight of oil applied. The oil was ignited with a small butane torch for 10 seconds, following the procedure of Brandvik et al. [20]. If the oil did not ignite, the procedure was repeated a total of up to three times. The oil was considered not ignitable if it did not ignite on the third trial. After flame extinction, the residues were collected by use of $3 \mathrm{M}$ absorption pads, which were then weighed on an accurate and precise scale. The burning efficiencies (in percent), $\eta$, were subsequently calculated as $\eta=100\left(1-\frac{m_{\text {res }}}{m_{\text {ini }}}\right)$, where $m_{\text {res }}$ is the mass residue of the oil after the burn and $m_{\text {ini }}$ is the initial mass of the oil.

A temperature profile was determined by measuring the temperature at the oil surface level, as well as at the points 2, 3, 5, 10, 20, 30, 40 and $50 \mathrm{~mm}$ below the oil surface level, and 150, 400 and $1000 \mathrm{~mm}$ above the oil surface level, see Fig. 3. Type K thermocouples were used and the temperatures were recorded every second by use of an Agilent data acquisition system connected to a PC. The exact height of all measurement points was carefully adjusted before each experiment to ensure that the surface reference points were positioned correctly. 
In order to determine the flame height, all experiments were recorded with a video camera. Prior to the experiments, the video camera was positioned to have a horizontal angle to the point of objective in order to ensure an equal relation between number of pixels and a given distance. A ruler was placed on the PGC and a reference still frame was taken with the same resolution as the video recordings to obtain a reference between distance and pixels (pixels/cm).

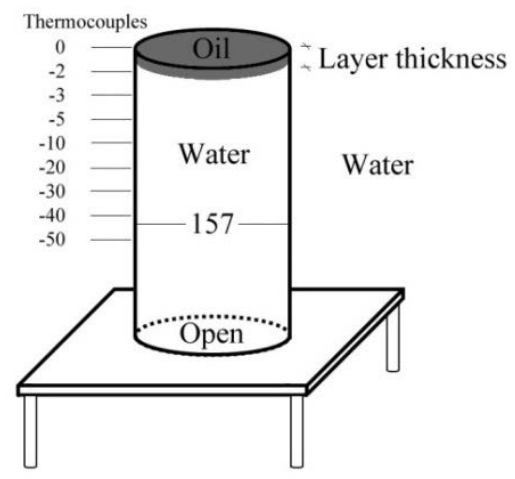

Fig. 3. Schematic of the PGC placed on a stainless steel foot. All numbers are in mm.

None of the experiments were extinguished manually, not even the ones where the crude oil caused violent boilover. Fig. 4 provides photographs of the burning experiments in the COFA, both for regular burning and boilover and for the post-extinction clean-up situation. Clearly, boilover, causes a more challenging post-extinction clean-up situation, as the oil is spread out over a significantly larger area. Still, given the large water surface compared to the size of the diameter of the oil spill, close to all the residue oil could be collected with the absorption pads. In addition, it is worth noting that boilover, due to its potential danger for the surroundings, should be included in the precautions set-up prior to an potential large scale experiment are being conducted.

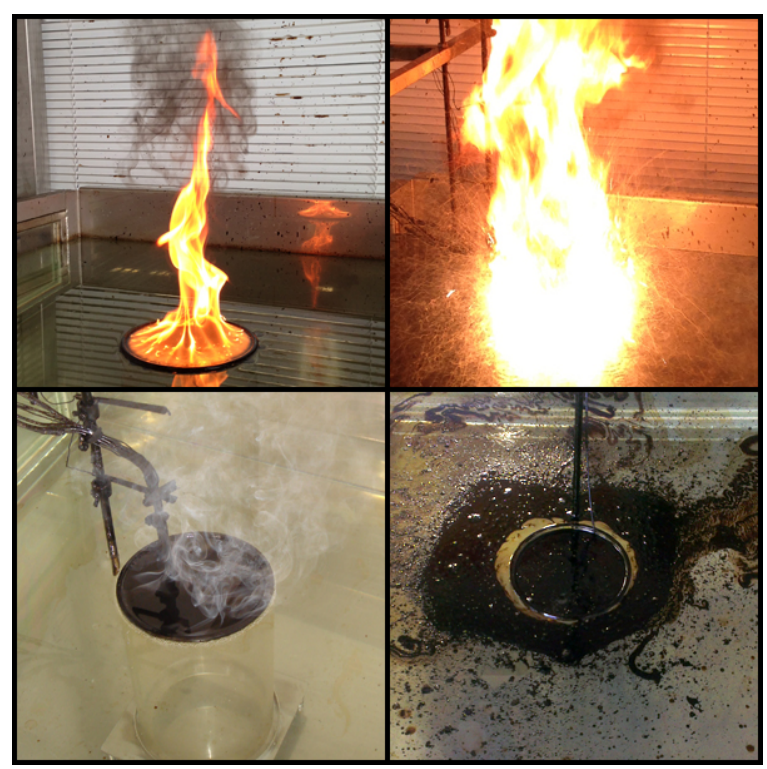

Fig. 4. Top left: Regular burning pre-boilover. Top right: Boilover. Bottom left: After flame extinction with no boilover during burning. Bottom right: After flame extinction with boilover during burning. 
With time, the objective of the development of the COFA is to address different aspects related to in-situ burning. As shown in Fig. 5, some of the controlling parameters and phenomena related to in-situ burning such as oil slick thickness, weathering (emulsification), boilover (vigorous burning), burning efficiency and different oil types can be systematically investigated using the COFA. It is also possible to change the diameter size of the PGC and to control the water temperature to imitate e.g. Arctic conditions. Furthermore, the open-bottomed cylinders can also be placed on a foot without a hole, so as to create a closed system for water sampling for environmental aspects.

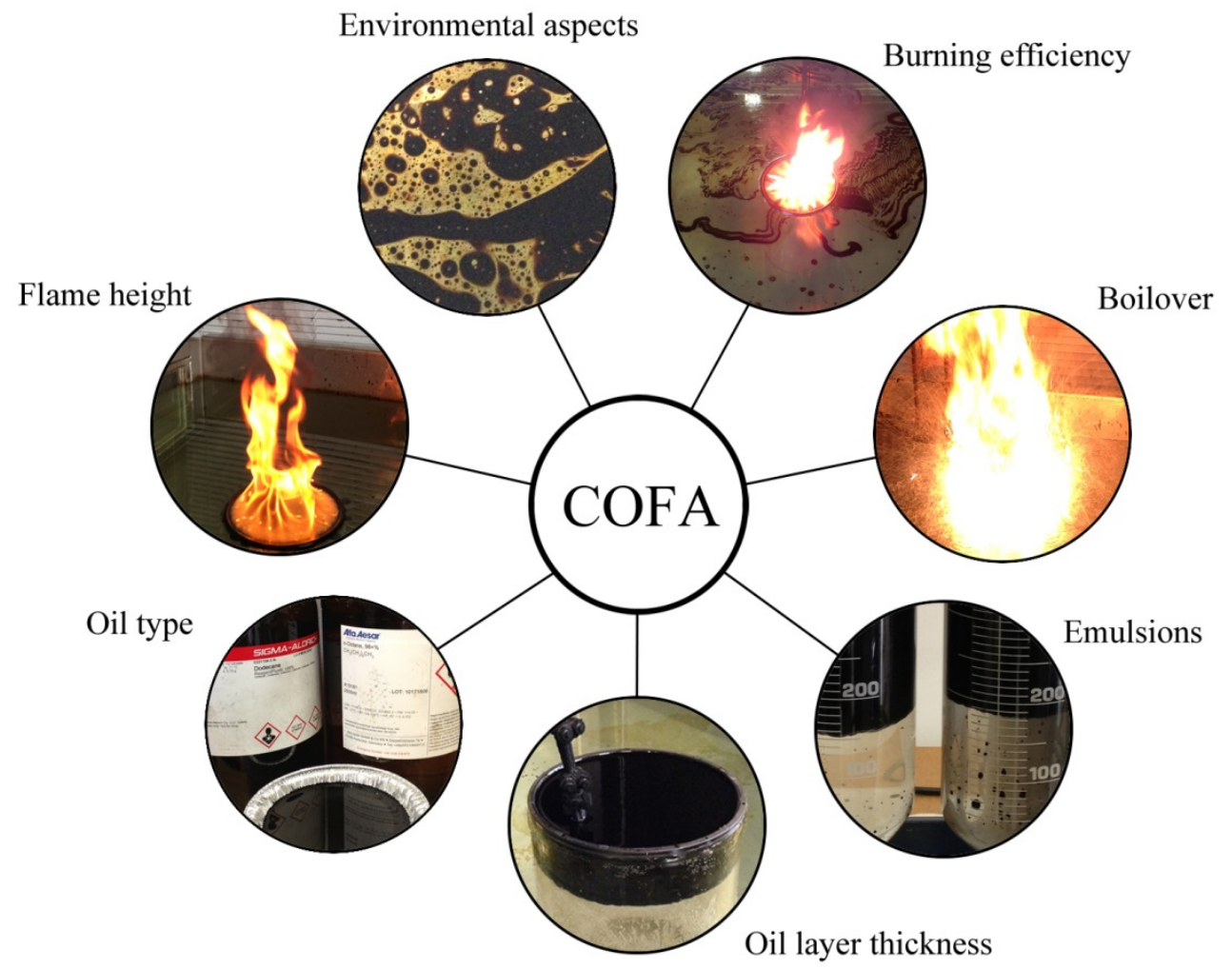

Fig. 5. Overview of the parameters, aspects and phenomena that can be studied in the COFA.

\section{EXPERIMENTAL RESULTS AND DISCUSSION}

The COFA is designed to analyze and measure the burning rate, the time to start of boilover, the boilover intensity, the liquid temperature history, and the burning efficiency of an oil layer on water. In this section, the experimental results obtained are compared with both existing data and existing theoretical correlations.

\section{Regression rate}

The surface regression rate as a function of the initial fuel layer thickness for a pool diameter of $15.7 \mathrm{~cm}$ for different fuels (the single component n-Octane and dodecane and the multicomponent Grane crude) is shown in Fig. 6. Data from prior studies found in the literature is also depicted. The experimental data denote average regression rate, which in our study denotes the average of period of time after ignition where the regression rate reaches a steady state. Some studies also define it as the pre-boilover regression rate $[13,21]$. During combustion the upper edge of the fuel layer was held constant by adding water to the external reservoir. This ensured that the influence due to ullage effects could be negligible. In some experimental trials, when the fuel layer becomes very thin due to continuous burning, the regression rate increases significantly (and almost instantly) resulting in boilover [16, 21, 22]. This behavior was also observed in the current study and is further discussed in the next section. 


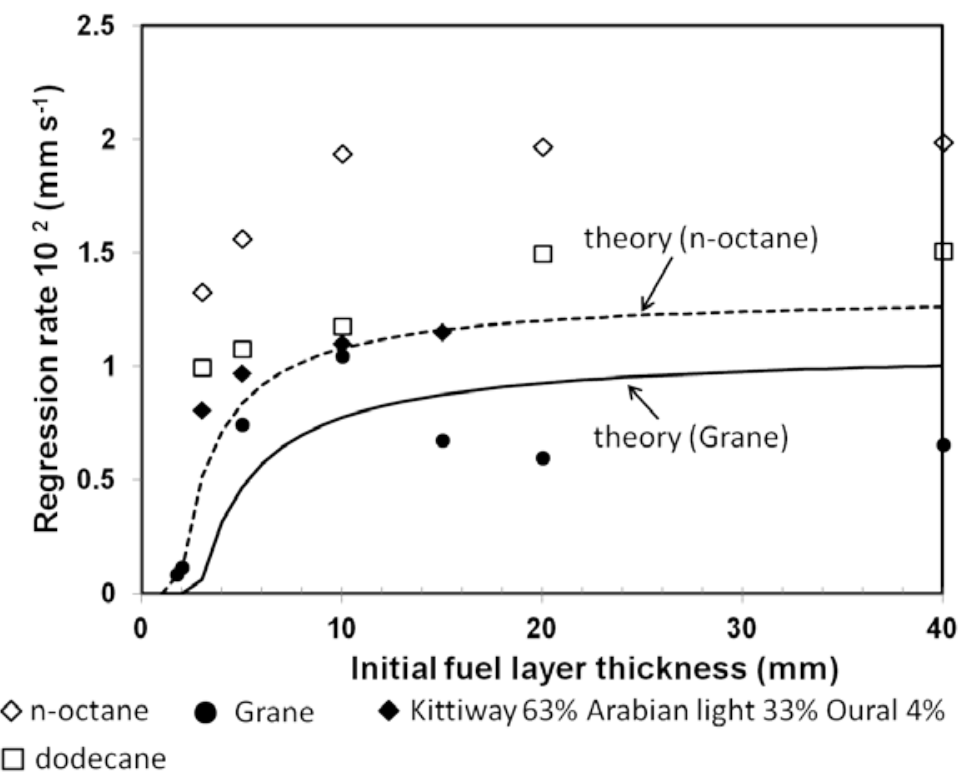

Fig. 6. Regression rates as a function of initial oil layer thickness.

The results for Kittiway 63\%, Arabian light 33\%, Oural 4\% is from [23].

From Fig. 6 it can be seen that the regression rate increases with thickness and then reaches a constant value. As observed in Fig. 6, the attainment of the constant value appears to be a function of the type of fuel. The constant regression rate is approached at a thickness of approximately $10 \mathrm{~mm}$ and $20 \mathrm{~mm}$ for $\mathrm{n}$ Octane and dodecane, respectively. This difference is mainly due to the difference in flash point (FP) of the two fuels. Dodecane $\left(\mathrm{FP}=71^{\circ} \mathrm{C}\right.$ ) requires more heat to sustain a steady combustion compared with nOctane, which has a FP of $15^{\circ} \mathrm{C}$. Garo et al. [12] have shown that this constant value increases with pool diameter. A similar trend was observed in the current experiments as shown in Fig. 7 for n-Octane.

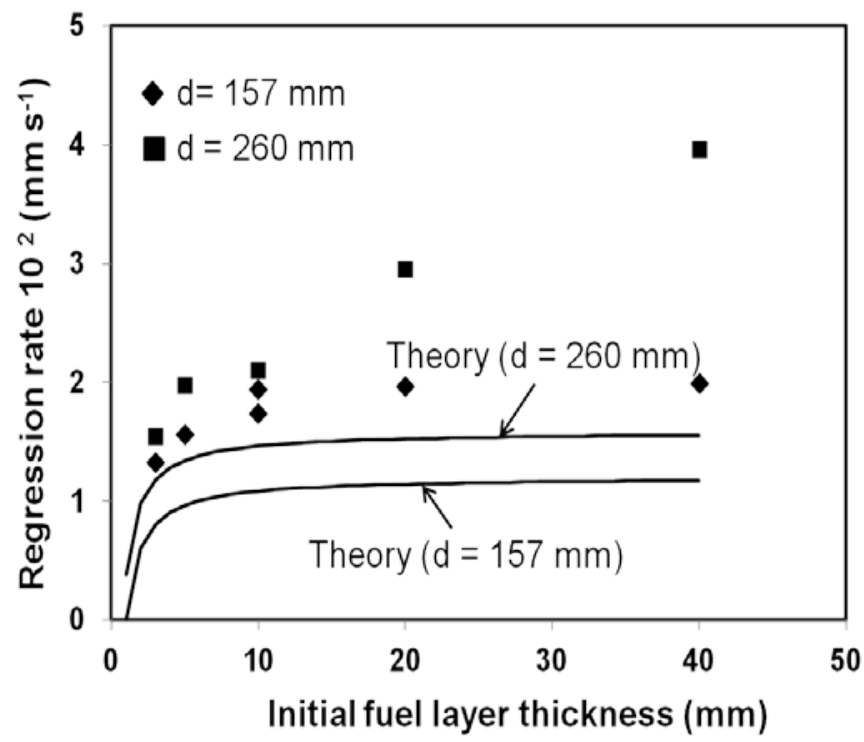

Fig. 7. Regression rate vs. initial fuel layer thickness of n-Octane for two different pool diameters. 
The reason for that the regression rate follows the trends depicted in Figs. 6 and 7 have been attributed to the heat losses due to the water underneath [24]. The thermal diffusivity of water is larger than that of fuels (see Table 1 below), thus, as the fuel layer thickness decreases (due to consumption of the fuel as it burns) the water layer approaches closer to the fuel surface, which vaporizes usually at a temperature a few degrees lower than the boiling point of the fuel. As the fuel layer thickness decreases the water acts as a heat sink and the burning rate decreases. It is interesting to note that the same trends are observed for all fuels tested. However, the limiting burning rate is different for each fuel (with same diameter) mainly due to the difference in the B-number. A theoretical model only assuming conduction and neglecting losses due to convective motion of the liquid and water was developed by $\mathrm{Wu}$ et al. [13] from where the regression rate, $r$, is expressed as:

$$
r=\frac{1}{H_{v} \rho_{F}}\left[\chi\left(\frac{\left(4 \rho_{\infty} C_{p}\left(T_{\infty} g\left(T_{f}-T_{\infty}\right)\right)^{1 / 2}\right)}{\pi}\right) d^{1 / 2}-\frac{\alpha_{F} \lambda_{F}\left(T_{S}-T_{\infty}\right)}{y_{o}\left(\sqrt{\alpha_{F}}+\sqrt{\alpha_{W}}\right)^{2}}\right] .
$$

The model assumes an overall thermal diffusivity of the system (oil $\left(\alpha_{F}\right)$ and water $\left.\left(\alpha_{W)}\right)\right)$. $H_{v}$ represents the latent heat of vaporization of the fuel, $\rho_{\mathrm{F}}$ the fuel density, $d$ is the diameter and $y_{o}$ is the initial fuel layer thickness. $\rho_{\infty}, C_{p}$ and $T_{\infty}$ represent the density, specific heat and ambient temperature of air, respectively. $T_{f}$ represents an approximate flame temperature, which is taken as $1100 \mathrm{~K}$ [13], and $\chi$ reperesents the fraction of the total heat release that is fed back per unit area to the fuel. The solid lines in Fig. 6 show the regression rate obtained using Equation 1, using the properties in Table 1. For all data points, $\chi$ was set equal to $2.9 \cdot 10^{-3}$ which was similar to the value used by Torero et al. [18].

As shown in Fig. 6, the model results for n-Octane follow the same trend as the experimental data for the smaller PGC diameter, and the quantitative prediction is generally better for the smaller fuel layer thicknesses. For large fuel layer thicknesses, the model and the experimental results differ in trend, especially for the larger PGC diameter. However, a steady regression rate is expected for thicker fuel layers. In the case of n-Octane, the model consistently underpredicts the experimental data, whereas for Grane the model underpredicts the experimental data for thickness of oil below $10 \mathrm{~mm}$, but overpredicts the experimental data for thicknesses larger than $10 \mathrm{~mm}$. In general, Eq. 1 can be used as an effective engineering tool if properties of the oil (thermal diffusivity, density surface temperature, heat of gasification) are known. However, these parameters are difficult to determine for the crude oil (Grane) due to its multicomponent nature. Also, the fraction of heat fed back to the fuel surface is a very important parameter, however it is also the most difficult parameter to determine and scale. Models that consider more parameters exists and are discussed by Hristov et al. [19]. However, these models generally do not solve the problem, as they show similar trends and further complications that necessitate additional research in developing effective experimental bench scale tests to extract realistic fuel/fire properties that are scalable.

Table 1. Properties of the pure oils and the crude oils used to solve Eqs. 1 and 2.

\begin{tabular}{|c|c|c|c|c|c|c|c|}
\hline & $\begin{array}{c}\mathbf{T}_{\mathbf{b}} \\
\left.\mathbf{(}^{\mathbf{0}} \mathbf{C}\right)\end{array}$ & $\begin{array}{c}\mathbf{T}_{\mathbf{F P}} \\
\left({ }^{\mathbf{0}} \mathbf{C}\right)\end{array}$ & $\boldsymbol{\alpha ( \mathbf { 1 0 } ^ { - 7 } \mathbf { m } ^ { 2 } / \mathbf { s } )}$ & $\begin{array}{c}\lambda \\
(\mathbf{W} / \mathbf{m}-\mathbf{K})\end{array}$ & $\begin{array}{c}\mathbf{H}_{\mathbf{v}} \\
(\mathbf{k J} / \mathbf{k g})\end{array}$ & $\mathbf{P}\left(\mathbf{k g} / \mathbf{m}^{3}\right)$ & $\begin{array}{c}\mathbf{C}_{\mathbf{p}} \\
(\mathbf{k J} / \mathbf{k g}-\mathbf{K})\end{array}$ \\
\hline Grane (crude oil) & $300-400$ & 23.5 & 0.68 & 0.132 & 250 & 941 & 2.3 \\
\hline n-Octane & 125 & 15 & 0.95 & 0.15 & 300 & 703 & 2.2 \\
\hline Dodecane & $215-225$ & 71 & 0.85 & 0.14 & 256 & 750 & 2.2 \\
\hline Water & 100 & - & 1.4 & 0.59 & 2257 & 998 & 4.18 \\
\hline Air & - & & 225 & 0.026 & - & 1.16 & 1 \\
\hline
\end{tabular}

\section{Boilover}

An illustration of the phenomena of rapid ejection of the fuel, which is usually called thin-layer boilover or vigorous burning in the in-situ burning literature, is shown in Figs. 4 and 5. The time to onset of boilover is an important consideration during the in-situ burning of crude oil as the process has been found to increase 
the removal rate significantly [25]. Table 2 shows the minimum thickness values for ignition and boilover for the different fuels tested in the COFA.

Table 2. Required oil layer thickness for ignition and boilover of the respective oils.

\begin{tabular}{|l|c|c|c|c|}
\hline Oil & $\begin{array}{c}\text { Minimum initial } \\
\text { oil slick thickness } \\
\text { for ignition [mm] }\end{array}$ & Boilover & $\begin{array}{c}\text { Asphaltenes } \\
\text { (wt. \%) }\end{array}$ & $\begin{array}{c}\text { Wax } \\
\text { (wt. \%) }\end{array}$ \\
\hline Grane (Crude oil) & $1.75-2$ & $\begin{array}{c}\text { Yes } \\
\text { (Initial oil slick } \\
\text { thickness }<15-20 \mathrm{~mm})\end{array}$ & $1.4^{\mathrm{a}}$ & $3.2^{\mathrm{a}}$ \\
\hline n-Octane (Pure oil) & $<1$ & No & - & - \\
\hline $\begin{array}{l}\text { Dodecane (Pure } \\
\text { oil) }\end{array}$ & $2-3$ & $\begin{array}{c}\text { Slight } \\
\text { (Initial oil slick } \\
\text { thickness }>2-3 \mathrm{~mm})\end{array}$ & - & - \\
\hline
\end{tabular}

${ }^{\mathrm{a}}$ Values from Brandvik et al. [10].

In order to reach the boilover state, it is essential that the fuel has a boiling point considerably higher than that of the underlying water, i.e. considerably higher than $100^{\circ} \mathrm{C}$. Due to the relatively low boiling points for n-Octane and dodecane, boilover is assumed to be of little or no significance for these pure oils. These assumptions were confirmed in the experiments, where there were no boilover for n-Octane and boilover was only observed in very limited form for some of the experiments with dodecane. The results for dodecane (boiling point of approximately $225^{\circ} \mathrm{C}$ ) indicate that this boiling point is located at the borderline between occurrence and no occurrence of boilover.

Boilover, however, was clearly observed for Grane crude oil, as shown in Fig. 8, for the thicknesses less than $15-20 \mathrm{~mm}$. Fig. 8 also shows the temperature history at the surface and down to $10 \mathrm{~mm}$ below the surface of the burning oil for 10 and $20 \mathrm{~mm}$ initial oil layer thicknesses. The location of the thermocouples were fixed throughout each experiment, thus the exact measuring points are individual for each oil due to the differences in density. For the $10 \mathrm{~mm}$ initial oil (Grane) slick thickness experiment (depicted by the darker colored curves in Fig. 8), the thermocouple located at $10 \mathrm{~mm}$ below the fuel surface are expected to represent the temperature of the water layer below the oil a few minutes after ignition. It is observed that the temperature of this water layer increases to about $100-120^{\circ} \mathrm{C}$ after about $600 \mathrm{~s}$ of burning. At this stage the temperature of the water sublayer is high enough to cause the formation of tiny water-vapor bubbles which are violently ejected out along with the fuel. Fig. 8 also illustrates that Grane with initial oil layer thicknesses above 15-20 mm does not boilover. The temperature $10 \mathrm{~mm}$ below the liquid fuel surface does not go beyond $\sim 80^{\circ} \mathrm{C}$ as shown in Fig. 8 by the gray dashed curve. This behavior is attributed to possible be a result of the creation of an almost impenetrable solid layer, which blocks the heat transfer that is necessary to superheat the underlying water to each necessary temperature of about $110-120^{\circ} \mathrm{C}$. This behavior merits further studies.

The time to boilover can also be predicted using a one dimensional heat transfer model developed by Wu et al. [13] and given by:

$$
t_{B O} \approx \frac{y_{o}^{2}}{\alpha_{F}+y_{o} r} .
$$

In Eq. 2, $y_{o}$ is the initial fuel layer thickness and $\alpha_{F}$ is the thermal diffusivity of the fuel. Using an average regression rate, $r$, of $0.55 \cdot 10^{-2} \mathrm{~mm} / \mathrm{s}$ for Grane (see Fig. 6) and substituting values of thermal diffusivity from Table 1, the time to boilover for a $10 \mathrm{~mm}$ initial thickness equals $800 \mathrm{~s}$ which compares reasonably well with the experimentally observed value of $730 \mathrm{~s}$. 


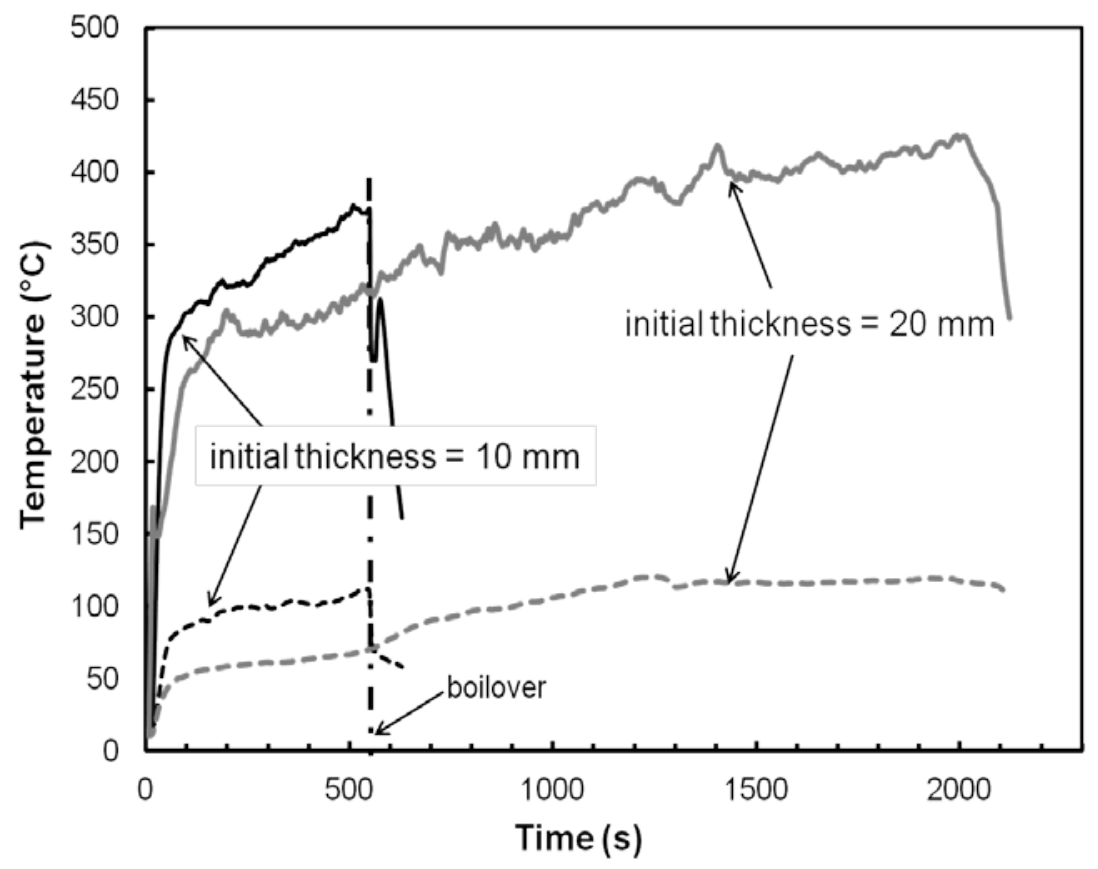

Fig. 8. Temperature profiles at surface (solid lines) and $10 \mathrm{~mm}$ below surface (dashed lines) for 10 (black color) and 20 (grey color) mm of Grane. Boilover (denoted by the vertical dot-dashed line) occurs with 10 $\mathrm{mm}$ but not with $20 \mathrm{~mm}$.

\section{Burning efficiency}

Figure 9 illustrates the burning efficiency as a function of the oil layer thickness for the different oil types. Owing to its high volatility (low flash point of $15^{\circ} \mathrm{C}$ ) n-Octane has the highest burning efficiency of 99$100 \%$. A test with an n-Octane layer thickness of $0.5 \mathrm{~mm}$ was performed and the result was identical, concluding that n-Octane is an efficient fuel with excellent burning properties even on top of water. Dodecane has a flashpoint far above room temperature, as shown in Table 1. Therefore, burning efficiencies less than $100 \%$ are reasonable, as the water underneath the oil will work as a cooling agent. Thin layers of Dodecane (less than 2-3 mm) were found to be non-ignitable, presumably for this reason. The burning efficiency was constant for initial oil layer thicknesses of 3-10 mm . However, the burning efficiency was slightly higher with an initial oil layer thickness above $10 \mathrm{~mm}$, as this caused the oil to reach a temperature that allowed for a larger part of the oil to be burned before being cooled down to the point of extinction by the water underneath.

The significant increase in the Grane crude oil burning efficiency as a function of initial oil layer thicknesses is also related to the violent boilover that occurs for initial oil layer thicknesses below 15-20 $\mathrm{mm}$. As discussed earlier, boilover does not occur, or occur in very little form, for an initial layer above 20 $\mathrm{mm}$. Due to the lack of boilover, the burning efficiency seems to be constant for an initial oil layer thickness of 20-80 $\mathrm{mm}$ (the result for $80 \mathrm{~mm}$ are not included in Fig. 8). Due to the cooling from the water underneath, the point of extinction occurs at a certain slick thickness, which is almost independent of the initial slick thickness. Thus, it is expected that the burning efficiency increases as the initial oil slick thickness increases. 


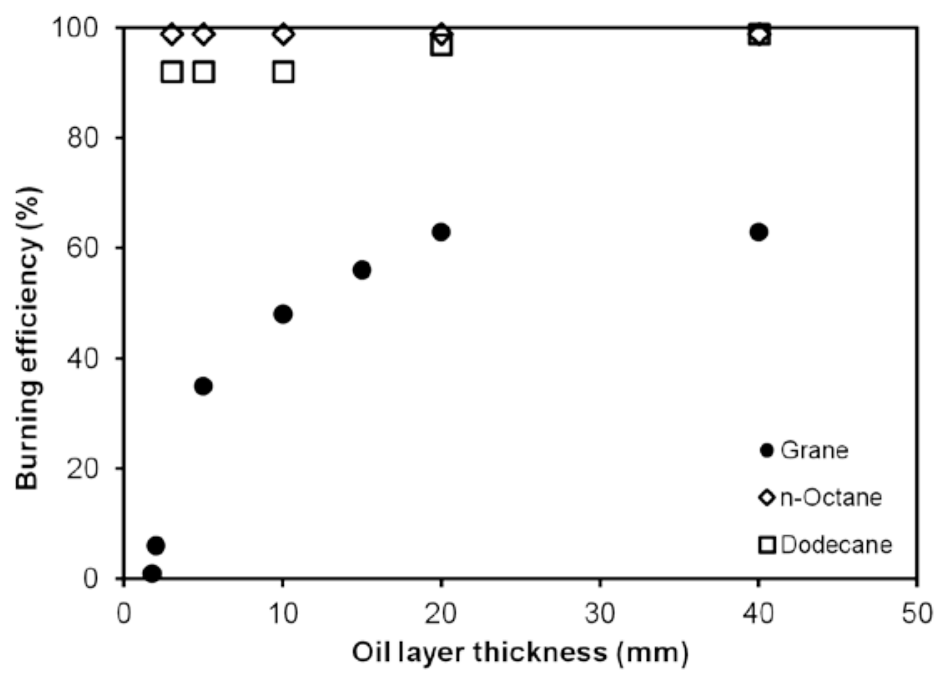

Fig. 9. Burning efficiency as a function of the oil layer thickness.

Grane consists of both short and long chained hydrocarbons, where the short hydrocarbons tend to burn first leaving the remaining oil with different properties, such as an increased flashpoint, density and viscosity. The higher flashpoint results in the relatively poor burning efficiency, as compared to that of the pure fuels. The change in properties for oil slicks thicknesses from around 15-20 mm, has in particular influence on the heat transfer trough the oil. By slowing the heat transfer at the interface between oil and water, it excludes the option of superheating the underlying water to the point of boilover occurrence. Furthermore, the water-bath underneath the oil acts as a cooling agent and is expected to influence the burning efficiency for particular the thinner oil slicks. Buist et al. [25] showed that the residue thickness is approximately constant $(1 \mathrm{~mm})$ for quiescent burns with initial oil slick thicknesses up to $40 \mathrm{~mm}$. This is in agreement with our findings.

Ignitability was only an issue for the initially very thin layers less than 2-3 mm and not an issue for nOctane. This is again related to the flashpoints of the fuels and the water functioning as a cooling agent, and our results are again in accordance with those of Buist et al. [25].

\section{Flame height}

The height of the flame was determined from the amount of pixels in the individual frames from the video recordings. Regarding the post processing of the video file in relation to measuring the flame height a program was developed to convert each frame of the video to binary code and to create subsections of 10 seconds. The requirement for the maximum height of the flame in each of these subsections was that the flame had to be present at least $60 \%$ of the time. This requirement was set to prevent the intermittent flame locations to be counted for as the flame height, and thereby reduce the sources of error in the estimate.

Figure 10 illustrates the respective flame heights of Grane, dodecane and n-Octane for a layer thickness of $10 \mathrm{~mm}$ and a pool diameter of $157 \mathrm{~mm}$. The flame height of the oils seem to increase at the same pace immediately after ignition, however the n-Octane and dodecane are both relatively volatile, producing significant flammable vapors which results in a much higher flame heights than that of Grane oil. Dodecane had about 10-15\% lower flame heights than n-Octane and Grane reaches approximately just half the flame height of n-Octane. The Grane experiment however, seems to produce more steady and less fluctuating flames. 
For n-Octane it is observed that the flame height does not change with initial oil slick thickness. The average flame height for the initial fuel layer thicknesses of 5, 10 and $40 \mathrm{~mm}$ equals $400 \mathrm{~mm}$. In the case of a multicomponent fuel (Grane) the flame height does not change significantly with initial oil layer thicknesses of 5, 10 and $20 \mathrm{~mm}$ either, and the average maximum steady flame height equals $220 \mathrm{~mm}$. However, the decrease in flame height as a function of burning time is observed to be slower with larger initial oil layer thicknesses. Grane is the only oil of the three to reach a significant boilover condition. When this occurs, the flame height is drastically increased. An estimation of a 1000-1200 mm of flame height is determined through observation on site and from video material. This estimate is not included in Fig. 10 and the estimated average maximum flame heights mentioned above.

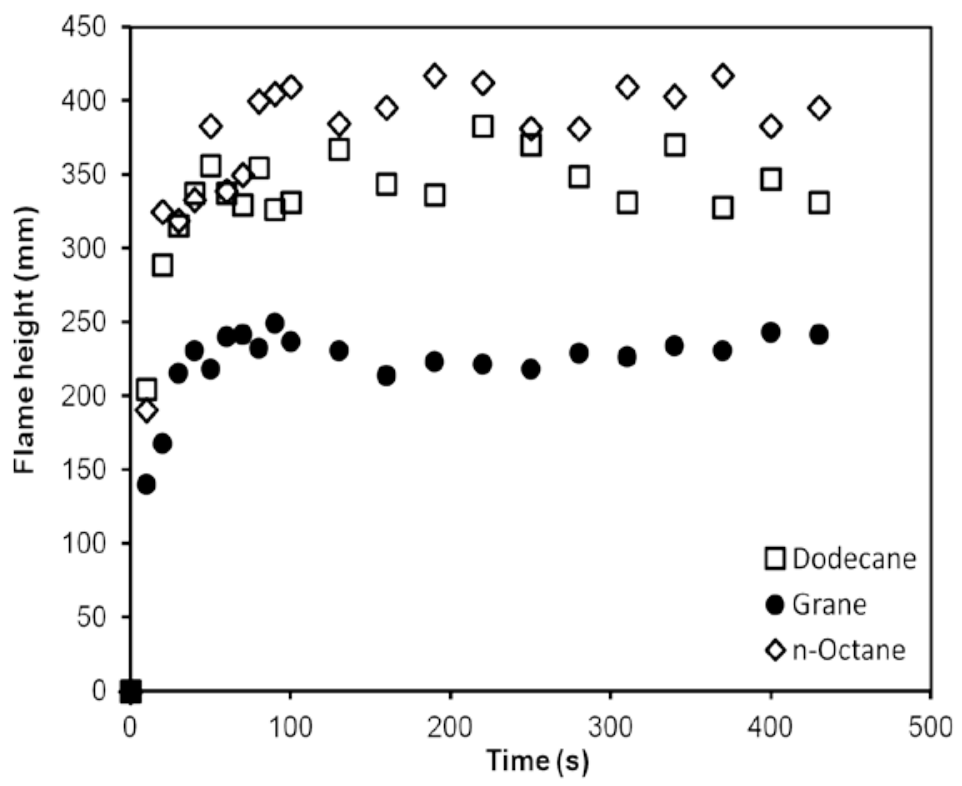

Fig. 10. Flame height as a function of time for the different oils.

\section{CONCLUSIONS}

The main objective of the study was to test and verify the newly constructed Crude Oil Flammability Apparatus (COFA), which has been designed to study the fire dynamics and heat transfer processes related to the burning of oil on water, to further understand burning of oil on water as a response technology (in situ burning) for accidental oil spills. The following parameters and phenomena were investigated for Grane crude oil, dodecane and n-Octane: burning efficiency, flame height, boilover and regression rate.

The burning efficiency was measured and found to be close to $100 \%$ for the pure oils, whereas the crude oil had a burning efficiency ranging from 35 to 65\%. The burning efficiency increased with increasing initial oil slick thickness, however for the experiments with 20, 40 and $80 \mathrm{~mm}$ initial oil slick thicknesses, the burning efficiency was found to be more or less constant around 60-65 \%.

During the experiments with Grane crude oil, boilover was observed for initial oil slick thicknesses of less than 15-20 mm. For thicker initial oil slicks, the temperature profile measurements found that the temperature in the lower part of the oil layer was less than the boiling point of water and thus the boilover did not occur. The measured temperature profiles indicated that a boiling point similar to that of dodecane $\left(225^{\circ} \mathrm{C}\right)$ or higher is required in order to cause boilover. For open water in-situ burning operations with 
crude oils having boiling points above $300^{\circ} \mathrm{C}$, the potential occurrence of boilover is therefore expected to be a possible issue.

Model results for n-Octane followed the same trend as the experimental data for the smaller PGC diameter, but for large fuel layer thicknesses, the model and the experimental results differed in trend, especially for the larger PGC diameter. However, that may be a results of that the fuel layer thickness has not been made large enough for a steady regression rate to be established. Future experiments are therefore planned with both larger diameter pans and larger initial oil layer thicknesses. In the case of n-Octane, the model consistently underestimates the experimental data, whereas the model overestimates the experimental data for the Grane crude oil.

It is concluded that the flame height is closely related to the volatility of the oil as n-Octane proves to achieve the largest flame heights. Dodecane had about 10-15\% lower flame heights and Grane reaches approximately just half the flame height of n-Octane. This is only the case during process of pre-boilover burning. When boilover initiates it becomes by far the largest flame height.

Based on the experiments in this paper the COFA have been found to be able to reproduce a realistic measure of crucial parameters to improve the understanding of the fire dynamics related to an in situ burning operation. Such information is necessary and should be included in an assessment prior to the approval and use of the method in case of an oil spill. Future experiments with the COFA include research to increase the knowledge base of, among other things, the toxicity of the burn residue.

\section{ACKNOWLEDGEMENTS}

The authors would like to thank COWIfonden for the grant that funded the experimental equipment and rig. We are also grateful to Statoil for supplying the crude oil.

\section{REFERENCES}

[1] Mosbech, A., "Potential Environmental Impacts of Oil Spills in Greenland - An assessment of information status and research needs”, National Environment Research Institute, NERI Technical Report No. 415, 2002, 117 p.

[2] Graham, B., Reilly, W.K., Beinecke, F., Boesch, D.F., Garcia, T.D., Murray, C.A., and Ulmer, F., "Deep Water: The Gulf Oil Disaster and the Future of Offshore Drilling,” Report to the President National Commission on the BP Deepwater Horizon. Oil Spill and Offshore Drilling, 2011, 355 p.

[3] Guenette, C.C. and Sveum, P., "In-situ Burning of Uncontained Crude Oil and Emulsions," Proceedings of the $18^{\text {th }}$ Arctic and Marine Oil spill Program (AMOP) Technical Seminar, Environment Canada, 1995, 2: pp. 997-1010.

[4] Walavalkar, A.Y. and Kulkarni, A.K., "Comprehensive Review of Oil Spill Combustion Studies,” Proceedings of the 9th Arctic and Marine Oil spill Program (AMOP) Technical Seminar: Environment Canada, 1986, pp. 1081-1103.

[5] Fritt-Rasmussen, J. and Brandvik, P.J., (2011) Measuring Ignitability for In-situ Burning of Oil Spills Weathered under Arctic Conditions: From Laboratory Studies to Large-scale Field Experiments. Marine Pollution Bulletin, 62(8): 1780-1785, http://dx.doi.org/10.1016/j.marpolbul.2011.05.020.

[6] Buist, I., McCourt, J., Potter, S., Ross, S., and Trudel, K., (1999) In Situ Burning, Pure Applied Chemistry, 71(1): 43-65, http://dx.doi.org/10.1351/pac199971010043.

[7] Buist, I., (2003) Window-of-Opportunity for In Situ Burning, Spill Science \& Technology Bulletin, 8(4): 341-346, http://dx.doi.org/10.1016/S1353-2561(03)00050-1. 
[8] Potter, S. and Buist, I., (2008) "In-situ Burning for Oil Spills in Arctic Waters: State-of-the-art and Future Research Needs”. Oil Spill Response: A Global Perspective, NATO Science for Peace and Security Series C: Environmental Security, pp. 23-39, http://dx.doi.org/10.1007/978-1-4020-85659_5.

[9] Nordvik, A.B., Champ, M.A., and Bitting, K.R., (2003) Estimating Time Windows for Burning Oil at Sea: Processes and Factors. Spill Science \& Technology Bulletin, 8(4): 347-359, http://dx.doi.org/10.1016/S1353-2561(03)00097-5.

[10] Brandvik, P.J., Fritt-Rasmussen, J., Reed, M., and Bodsberg, N.R., "Predicting Ignitability for In Situ Burning of Oil Spills as a Function of Oil Type and Weathering Degree,” Proceedings of the 33rd AMOP Technical Seminar on Environmental Contamination and Response, Environment Canada, Ottawa, ON, 2010. pp. 773-786.

[11] Fritt-Rasmussen, J., In Situ Burning of Arctic Marine Oil Spills. Ignitability of Various Oil Types Weathered at Different Ice Conditions. A Combined Laboratory and Field Study, Ph.D. Thesis, DTU Civil Engineering, 2010.

[12] Garo, J., Vantelon, J., and Fernandez-Pello C., (1994) Boilover Burning of Oil Spilled on Water, Proceedings of the Combustion Institute 25: 1481-1488, http://dx.doi.org/10.1016/S00820784(06)80792-7.

[13] Wu, N., Baker, M., Kolb, G., and Torero, J.L., (1996) Ignition, Flame Spread and Mass Burning Characteristics of Liquid Fuels on a Water Bed, Spill Science \& Technology Bulletin, 3(4): 209212, http://dx.doi.org/10.1016/S1353-2561(97)00014-5.

[14] Evans, D., Walton, W., Baum, H., Lawson, R., Rehm, R., Harris, R., Ghoniem, A., and Holland, J. "Measurement of large scale oil spill burns, ”Arctic and Marine Oil Spill Program Technical Seminar, Alberta, Canada, 1990.

[15] Allen, A., “Contained Controlled Burning of Spilled Oil during the Exxon Valdez Oil Spill”, Arctic and Marine Oil Spill Program, Edmonton, Alberta, 1990.

[16] Koseki, H., Mullholand, G., and Tadahisa, J., "Joint Study on Liquid Pool Fire between NIST/CFR and FRI - Part 1: Study on Combustion Property of Crude Oil”, Tenth joint panel meeting of the UJNR panel on fire research and safety, Berkeley, CA, 1989.

[17] Garo, J., Vantelon, J., and Fernandez-Pello, A. (1996) Effect of the Fuel Boiling Point on the Boilover Burning of Liquid Fuels Spilled on Water, Proceedings of the Combustion Institute 26: 1461-1467, http://dx.doi.org/10.1016/S0082-0784(96)80367-5.

[18] Torero, J.L., Olenick, S.M., Garo, J.P., and Vantelon, J.P., (2003), Determination of the Burning Characteristics of a Slick of Oil on Water, Spill Science \& Technology Bulletin, 8(4): 379-390, http://dx.doi.org/10.1016/S1353-2561(03)00071-9.

[19] Hristov, J., Planas-Cuchi, E., Arnaldos, J., and Casal, J., (2004) Accidental Burning of a Fuel Layer on a Waterbed: A Scale Analysis of the Models Predicting the Pre-boilover Time and Tests to Published Data, International Journal of Thermal Sciences, 43(3): 221-239, http://dx.doi.org/10.1016/j.ijthermalsci.2003.06.004.

[20] Brandvik, P.J., Leirvik, F., Fritt-Rasmussen, J., and Daniloff, R. "Using a Small Scale Laboratory Burning Cell to Measure Ignitability for In-situ Burning of Oil Spills as a Function of Weathering,” Arctic and Marine Oilspill Program Technical Seminar, Canada, 2010.

[21] Garo, J.P., Vantelon, J.P., Gandhi, S., and Torero, J.L. "Some Observations on the Pre-boilover Burning of a Slick of Oil on Water” Ministry of Supply and Services, Canada, 1996.

[22] Neil, W.U., Kolb, G., and Torero, J.L., (2000) The Effect of Weathering on the Flammability of a Slick of Crude Oil on a Waterbed, Combustion Science and Technology, 161(1): 269-308, http://dx.doi.org/10.1080/00102200008935820. 
[23] Garo, J.-P., Koseki, H., Vantelon, J.P., and Fernandez-Pello, C., (2007), Combustion of Liquid Fuels Floating on Water. Thermal Science, 2007. 11(2): 119-140, http://dx.doi.org/10.2298/TSCI0702119G.

[24] Garo, J.P., Vantelon, J.P., Gandhi, S., and Torero, J.L., (1999), Determination of the Thermal Efficiency of Pre-boilover Burning of a Slick of Oil on Water, Spill Science \& Technology Bulletin, 5(2): 141-151, http://dx.doi.org/10.1016/S1353-2561(98)00049-8.

[25] Buist, I.A., Ross, S.L., Trudel, B.K., Taylor, E., Campbell, T.G., Westphal, P.A., Myers, M.R., Ronzio, G.S., Allen, A.A., and Nordvik, A.B., "The Science, Technology, and Effects of Controlled Burning of Oil Spills at Sea,” Marine Spill Response Corp., Research and Development Program, 1994. 